\title{
Airborne mercury species at the Råö background monitoring site in Sweden: distribution of mercury as an effect of long-range transport
}

\author{
Ingvar Wängberg $^{1}$, Michelle G. Nerentorp Mastromonaco ${ }^{2}$, John Munthe ${ }^{1}$, and Katarina Gårdfeldt ${ }^{2}$ \\ ${ }^{1}$ IVL Swedish Environmental Research Institute, Gothenburg, 41133, Sweden \\ ${ }^{2}$ Department of Chemistry and Chemical engineering, Chalmers University of Technology, Gothenburg, 41296, Sweden
}

Correspondence to: Ingvar Wängberg (ingvar.wangberg@ivl.se)

Received: 16 June 2016 - Published in Atmos. Chem. Phys. Discuss.: 20 June 2016

Revised: 4 October 2016 - Accepted: 6 October 2016 - Published: 31 October 2016

\begin{abstract}
Within the EU-funded project, Global Mercury Observation System (GMOS) airborne mercury has been monitored at the background Råö measurement site on the western coast of Sweden from mid-May 2012 to the beginning of July 2013 and from the beginning of February 2014 to the end of May 2015. The following mercury species/fractions were measured: gaseous elemental mercury (GEM), particulate bound mercury (PBM) and gaseous oxidised mercury (GOM) using the Tekran measurement system. The mercury concentrations measured at the Råö site were found to be low in comparison to other, comparable, European measurement sites. A back-trajectory analysis to study the origin of air masses reaching the Råö site was performed. Due to the remote location of the Råö measurement station it receives background air about $60 \%$ of the time. However, elevated mercury concentrations arriving with air masses coming from the south-east are noticeable. GEM and PBM concentrations show a clear annual variation with the highest values occurring during winter, whereas the highest concentrations of GOM were obtained in spring and summer. An evaluation of the diurnal pattern of GOM, with peak concentrations at midday or in the early afternoon, which often is observed at remote places, shows that it is likely to be driven by local meteorology in a similar way to ozone. Evidence that a significant part of the GOM measured at the Råö site has been formed in free tropospheric air is presented.
\end{abstract}

\section{Introduction}

Mercury $(\mathrm{Hg})$ is a poisonous metal which occurs in the Earth's crust at low concentrations, primarily in the form of the mineral cinnabar $(\mathrm{HgS})$, i.e. mercury sulfide. The metal is unique in many ways as it has a lower melting point $\left(-39^{\circ} \mathrm{C}\right)$ and a lower boiling point $\left(357^{\circ} \mathrm{C}\right)$ than any other metal. This means that mercury is volatile at room temperature and may occur as gaseous elemental mercury (GEM), i.e. as $\mathrm{Hg}$ atoms, in the atmosphere. Other than the noble gases, mercury is the only element which occurs as an atomic gas at normal temperatures. Airborne mercury largely consists of GEM (>98\%) and small quantities of gaseous oxidised mercury (GOM), i.e. divalent gaseous mercury species, as well as particulate bound mercury (PBM). Mercury atoms are relatively stable, which means that they have a long residence time in the atmosphere (about a year; Schroeder and Munthe, 1998) and can be dispersed globally before they are oxidised and leave the atmosphere via wet or dry deposition. Atmospheric mercury rarely constitutes a direct risk to human health. The principal environmental concern regarding mercury is its ability to be converted to methylmercury which occurs by natural biological processes. Methylmercury is highly toxic and can bioconcentrate a million-fold in the food chain, which occurs frequently in marine and freshwater ecosystems. The latter has resulted in regulatory fish consumption guidelines and health advisories in Scandinavia and North America (Schroeder and Munthe, 1998). Atmospheric mercury has both natural and anthropogenic sources and is believed to have increased by a factor of 3 or more since industrialisation (Lamborg et al., 2002). The principal manmade emission sources of mercury are artisanal and 
small-scale gold production, coal combustion, non-ferrous and other primary metal production as well as cement production (Pacyna et al., 2016). Re-emission of mercury to the atmosphere is caused by reduction of deposited oxidised mercury on sea and land surfaces and enhances distribution and atmospheric exposure of mercury to the environment. Mercury, re-emitted to the atmosphere from sea and land surfaces, is assumed to be equal or even much larger than the total direct anthropogenic emissions (AMAP/UNEP, 2013). The largest natural emission sources of mercury are active volcanoes and weathering of bedrock and their contributions to the atmospheric burden of mercury are estimated to be less than $15-30 \%$ of the man-made emissions (AMAP/UNEP, 2013).

As a sub-task within the project Global Mercury Observation System (GMOS), funded by the EU Framework Program (FP7) for research, technological development and demonstration, the airborne mercury species, GEM, GOM and PBM were measured at the Råö measurement station situated on the western coast of Sweden. The Tekran speciation method was used to obtain values of high temporal resolution. The GOM and PBM measurements are operationally defined and may depend on the measurement method used. It has been argued that GOM, in particular, is subject to interferences from ozone, water vapour etc. when measured with the Tekran system (Jaffe et al., 2014). The chemical composition of GOM and mercury species on particles still remains an unresolved issue, which hampers development of better measurement techniques (Gustin et al., 2013, 2015). At present the only available automatic method for measuring GOM and PBM is the Tekran system, however.

Here, an evaluation of continuous measurements of GEM, GOM and PBM from 15 May 2012 to 3 July 2013 and 1 February 2014 to 31 May 2015 is presented and compared to the results from measurements made at other northern European sites using the same measurement method. The result of an evaluation of the origin of air masses reaching the measurement site is also presented and shows that most of the air entering the Råö site is of background origin. Evidence is presented that the highest concentrations of GOM measured at the Råö site arrived with air masses from the north, and to the most part are due to oxidation of GEM in the free troposphere. An alternative interpretation of the diurnal pattern of GOM, with peak concentrations at midday or in the early afternoon, is presented, which suggests that the variation in GOM is likely to be caused by a local meteorological phenomena rather than by local GOM formation within the boundary layer.

\section{Experimental section}

\subsection{Sampling site}

The Råö measurement station is a coastal site on the western coast of Sweden, about $50 \mathrm{~km}$ south of Gothenburg $\left(57^{\circ} 23^{\prime} 37.76 \mathrm{~N}, 11^{\circ} 54^{\prime} 50.73 \mathrm{E}, 7 \mathrm{~m}\right.$ above sea level) and is one of the GMOS master sites. The site is situated far away from major sources of air pollutants and the measurements are performed in background air most of the time. The annual average temperature, humidity and wind speed $( \pm 1$ standard deviation) at the site were $9 \pm 7{ }^{\circ} \mathrm{C}, 76 \pm 12 \%$ and $6 \pm 4 \mathrm{~m} \mathrm{~s}^{-1}$ respectively, based on measurements from 2012 to 2015 . The corresponding 25 th and 75 th percentiles were $4,14{ }^{\circ} \mathrm{C} ; 69,85 \%$ and $4,9 \mathrm{~m} \mathrm{~s}^{-1}$ respectively. The predominant wind direction at the site is south-westerly. From 2012 to 2014, the average annual precipitation amount was $720 \pm 120 \mathrm{~mm}$ at the Råö site.

\subsection{Methods}

\section{Fractionation of mercury species in air}

Mercury species in the air were measured using the Tekran mercury speciation system, which constitutes of the Tekran $1130 / 1135$ sampling modules in combination with the Tekran 1130 pump and control module and the mercury detector Tekran 2537B a cold vapour atomic fluorescence spectrometer (CVAFS) (Landis et al., 2002; Lindberg et al., 2002); see Fig. 1a and b. The Tekran mercury detector measures the amount of elemental mercury vapour trapped on one of two alternating gold traps after thermal desorption and fluorescence detection at $253.7 \mathrm{~nm}$. With the Tekran system, GEM, GOM and PBM were simultaneously measured. The sample air is pulled through an inlet impactor separating particles larger than $2.5 \mu \mathrm{m}$ at a flow rate of $10 \mathrm{~L} \mathrm{~min}^{-1}$. GOM is adsorbed on a $\mathrm{KCl}$-coated quartz glass denuder adjacent to the inlet. PBM is collected on a quartz glass fibre filter upstream the denuder, while GEM is passing through the system towards the 1130 pump module. Before the pump module the airflow is divided so that $1 \mathrm{~L} \mathrm{~min}^{-1}$ is pumped to the Tekran CVAFS detector and the rest goes to the pump module and is not analysed. While GOM and PBM are collected in the 1130/1135 modules, GEM values with a time resolution of $5 \mathrm{~min}$ were obtained. The present measurements of GOM and PBM were collected over $3 \mathrm{~h}$, followed by an analysis cycle of $60 \mathrm{~min}$. During the analysis no GEM measurement was taken. Every $4 \mathrm{~h}, 3 \mathrm{~h}$-averaged PBM and GOM values are obtained together with $5 \mathrm{~min}$-averaged GEM. Hence, all mercury values are obtained with a time coverage of $75 \%$. All mercury concentrations presented are normalised to air volumes at $273 \mathrm{~K}$ and $1 \mathrm{~atm}$. A description on the Tekran speciation system can be found on the home page of Tekran Instruments Corporation, http://www.tekran.com/files/facts_ 1135_r102.pdf. 
(a)

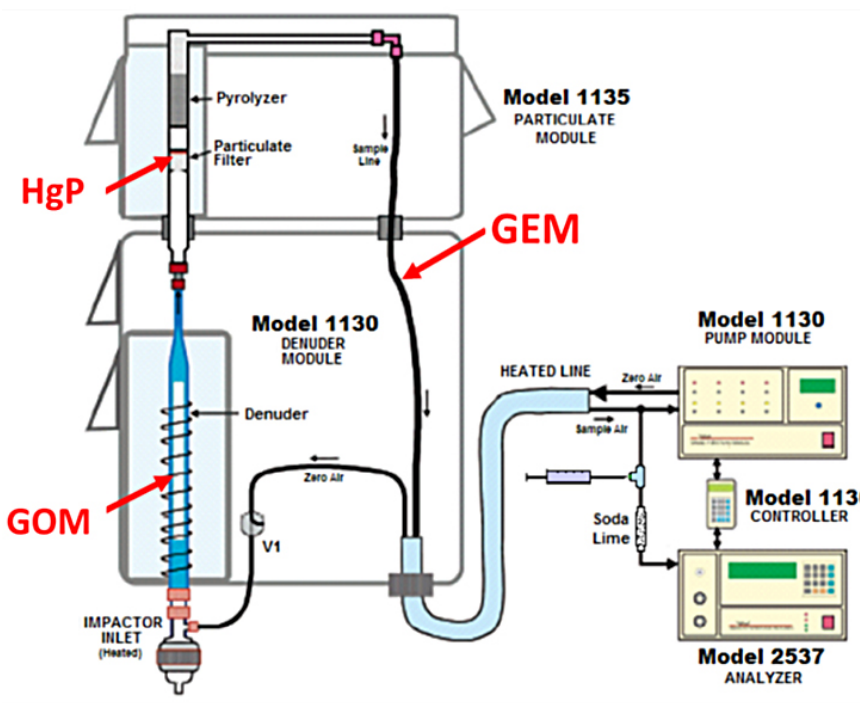

(b)

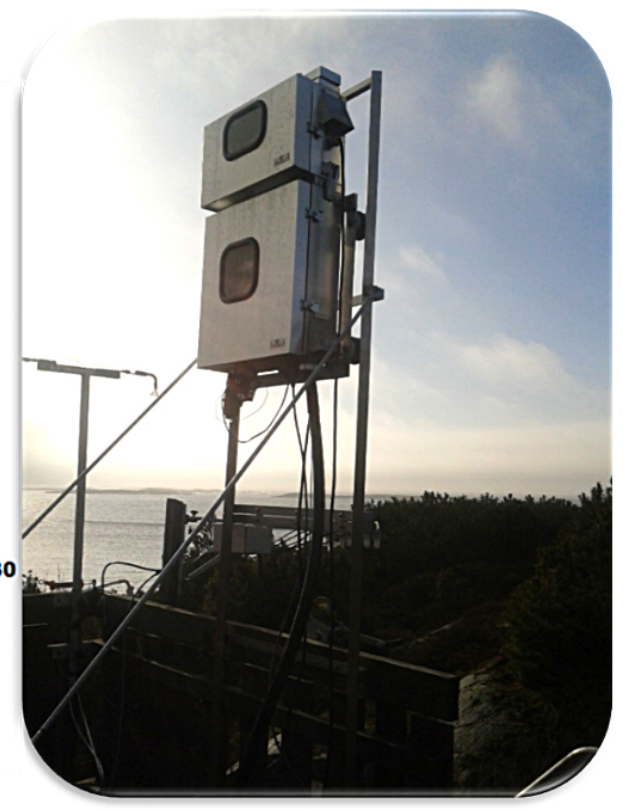

Figure 1. (a) A schematic overview of the Tekran mercury speciation system 1130/35 and the 2537 mercury analyser, (b) picture of the instrument operating at the Råö station.

The average detection limit of GEM was found to be $<0.02 \mathrm{ng} \mathrm{m}^{-3}$ based on calculations of $3 \times$ standard deviation of GEM blanks using zero air values obtained prior to each PBM and GOM analysis cycle. No reproducibility test was performed but the reproducibility is typically $12 \%$ according to Weigelt et al. (2013). The instrument was set to automatically calibrate every $73 \mathrm{~h}$ using the internal permeation source. The accuracy of the internal permeation source was tested every 6 months against manual $\mathrm{Hg}$ vapour injections using a laboratory built thermostat-controlled mercury vapour source, following the CEN calibration procedure (Brown et al., 2010). Since the two calibration methods agreed within $5 \%$, no adjustments of the internal mercury calibration source were performed for the present measurements. Since the concentrations of GOM and PBM are very low at the Råö site, a large effort was made to limit blanks in the measurement system. The analysis of PBM and GOM occurred during three, 5 min-long analysis cycles. Once the blanks are at the appropriate level, PBM and GOM were always detected during their first analysis cycles. In the following two cycles the $\mathrm{Hg}$ concentration were mostly equal to zero. For both PBM and GOM the results from the last analysis cycles, when both the PBM trap and the denuder were at high temperature, were considered to represent blank values. Three times the standard deviation of blanks using all data yielded an average detection limit of $0.11 \mathrm{pg} \mathrm{m}^{-3}$ for PBM and an average detection limit of $0.23 \mathrm{pg} \mathrm{m}^{-3}$ for GOM. However, as reported by Swartzendruber et al. (2009) and Slemr et al. (2016), the Tekran instrument tends to underestimate low concentrations and the authors suggest that a recalculation procedure should be performed. According to these findings, the low PBM and GOM values and the reported detection limits are especially erroneous. Due to a lack of the necessary data, i.e. fluorescence signal vs. time from each analysis, no recalculation was performed. This means that GOM and PBM values lower than $2 \mathrm{pg} \mathrm{m}^{-3}$ are likely to be underestimated. Evaluation of measurement results and maintenance of the Tekran instruments were made according to the standard operational procedure developed within the GMOS project (http://www.gmos.eu/) that is harmonised with the operational procedures used in the USA and Canada (Olson and Rhodes, 2011; Steffen et al., 2012). Average and median values of GEM, PBM and GOM were calculated using all data including PBM and GOM zero values. In the evaluation of the weather condition for each measurement day, Lamb weather types and precipitation data were used.

\subsection{Back-trajectory evaluation}

The Hybrid Single-Particle Lagrangian Integrated Trajectory (HYSPLIT) 4.0 model (Draxler, 2003) was used to produce back-trajectories starting at the Råö site. The HYSPLIT programme was run with meteorological analysed fields from the NCEP/NCAR reanalysis project, a joint effort between the National Centers for Environmental Prediction (NCEP) and the National Center for Atmospheric Research (NCAR). The input meteorological data had $2.5^{\circ}$ horizontal resolution, with 18 vertical pressure levels extending between 1 and $1000 \mathrm{hPa}$. For the purpose of this study, trajectories were released at 5 different vertical levels (10, 50, 100, 250 and $500 \mathrm{~m}$ ) every $4 \mathrm{~h}$ to get a good representation of the trans- 
(a)

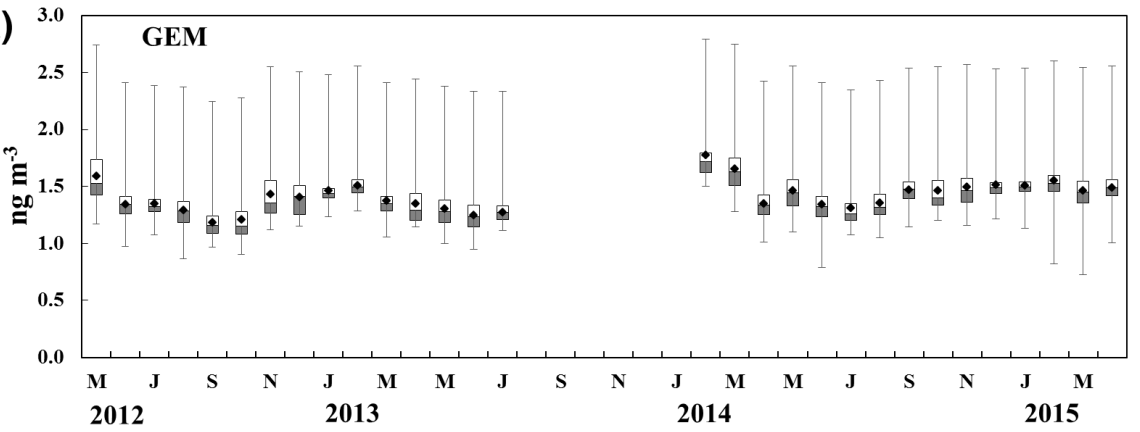

(b)

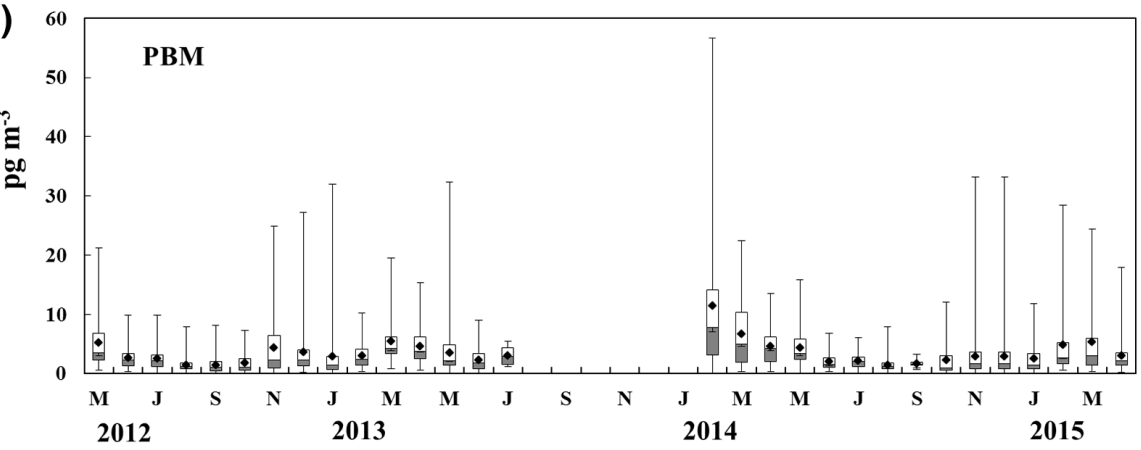

(c)

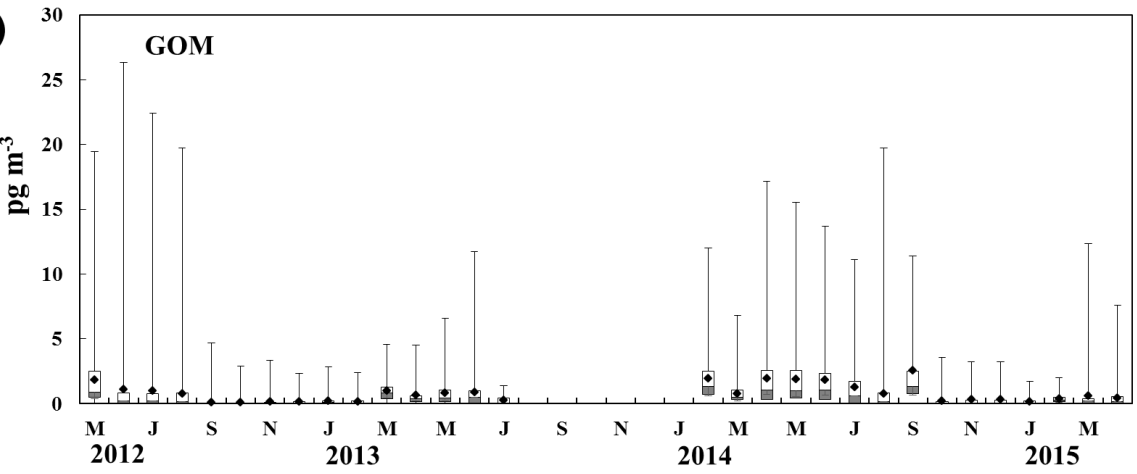

Figure 2. Box plots of measured (a) GEM, (b) PBM and (c) GOM at Råö/Rörvik from May 2012 to July 2013 and from February 2014 to April 2015. Diamonds show average values. Upper and lower boxes show 75 and $25 \%$ percentiles respectively with median values in between. Upper and lower whisker bars show maximum and minimum values.

port pathways into the target region. From each of the points a trajectory was started and run backwards in time for $72 \mathrm{~h}$ (3 days). Six back-trajectories were calculated for each day to match each of the six daily analysis cycles of GOM and PBM. To evaluate the mercury concentration as a function of the origin of air masses, the area around Råö was divided into $16,22.5^{\circ}$-wide sectors. There are no known emission sources that are large enough to influence the mercury concentrations at the measurement site within a circle of $150 \mathrm{~km}$. Geographical points on each trajectory associated with the 16 sectors outside the $150 \mathrm{~km}$ circle were identified with the help of a specially developed Excel Visual Basic for Applications (VBA) software. Evaluation of back-trajectories showed that no significant difference could be seen between back-trajectories starting at 100 and at $250 \mathrm{~m}$, and the other starting heights gave very similar results. Those at $250 \mathrm{~m}$ were chosen in the following evaluation. With this computer programme, the involved sectors could be associated with each individual mercury measurement. Altogether, the origins of air masses associated to 4193 mercury speciation measurements were evaluated.

\section{Results and discussion}

\subsection{Measured values}

Medians and arithmetic means of the mercury concentrations measured at Råö during the period from 15 May 2012 to 29 April 2015 are presented in Table 1 and are compared to mercury values obtained at other northern European sites. The variation of the average data is indicated as \pm 1 standard deviation. Mace Head is a Global Atmospheric 
Table 1. Median and average mercury concentrations measured at some northern European sites.

\begin{tabular}{|c|c|c|c|c|c|}
\hline Measurement sites & $\begin{array}{r}\text { GEM/TGM } \\
\text { median } \\
\mathrm{ng} \mathrm{m}^{-3}\end{array}$ & $\begin{array}{r}\text { GOM } \\
\text { median } \\
\operatorname{pg~m}^{-3}\end{array}$ & $\begin{array}{r}\text { PBM } \\
\text { median } \\
\operatorname{pg~m}^{-3}\end{array}$ & Period & Reference \\
\hline Råö & 1.41 & 0.23 & 2.21 & $2012-2015$ & This work \\
\hline Mace Head* & 1.48 & - & - & 2012-2015 & \\
\hline \multirow[t]{2}{*}{ Waldhof } & 1.61 & 1.0 & 6.30 & 2009-2011 & Weigelt et al. (2013) \\
\hline & $\begin{array}{l}\text { Average } \\
\text { ng m }^{-3}\end{array}$ & $\begin{array}{l}\text { Average } \\
\mathrm{pg} \mathrm{m}^{-3}\end{array}$ & $\begin{array}{l}\text { Average } \\
\text { pg m }^{-3}\end{array}$ & & \\
\hline Råö & $1.42 \pm 0.20$ & $0.80 \pm 1.6$ & $3.6 \pm 4.5$ & $2012-2015$ & This work \\
\hline Mace Head* & $1.48 \pm 0.14$ & - & - & $2012-2015$ & \\
\hline Aucgencort Moss & $1.40 \pm 0.19$ & $0.43 \pm 1.7$ & $3.1 \pm 5.3$ & 2009-2011 & Kentisbeer et al. (2014) \\
\hline Harwell* & $1.45 \pm 0.24$ & - & - & $2012-2013$ & Kentisbeer et al. (2015) \\
\hline
\end{tabular}

* Total gaseous mercury measured with Tekran instruments, calculated for the same periods as in this work.

Watch (GAW) station on the western coast of Ireland. Aucgencort Moss and Harwell are rural background inland sites in southern Scotland and Oxfordshire, England respectively, whereas Waldhof is a rural inland background site situated $100 \mathrm{~km}$ south-east of Hamburg in Germany. These measurements were performed using the same Tekran instruments as used in the present work. The measurements in Aucgencort Moss, Harwell and Waldhof were made some years earlier, and are, therefore, not directly comparable to the present measurements. As seen in Table 1, the TGM (total gaseous mercury) concentration at Mace Head is somewhat higher than at Råö. TGM measurements have been performed on these two stations on a regular basis since 1996 and the tendency of higher values on Mace Head appears to be consistent during the entire measurement period. The reason for this is not fully understood, but the higher TGM values at Mace Head have been attributed to mercury evasion from the North Atlantic Ocean (Wängberg et al., 2007a and references therein). The TGM/GEM values at Aucgencort Moss and Harwell are somewhat lower and are more similar to the Råö measurements. Regarding GOM and PBM, only data from Aucgencort Moss and Waldhof are available for comparison. The GOM concentration at Aucgencort Moss appears to be lower than at Råö whereas the PBM concentration is about the same. The highest concentrations of mercury species are found at Waldhof in Germany. As is discussed below, this is probably because the Waldorf site is relatively close to mercury emission sources in eastern Europe.

Monthly average GEM, PBM and GOM data are presented as box and whisker plots in Fig. 2. The GEM data is evenly distributed within a narrow range of $1.4-1.5 \mathrm{ng} \mathrm{m}^{-3}$ with occasional elevated values reaching above $2.5 \mathrm{ng} \mathrm{m}^{-3}$. The variation in concentration of PBM and GOM is much greater and varies from under the detection limit to $56 \mathrm{pg} \mathrm{m}^{-3}$ for PBM and $26 \mathrm{pg} \mathrm{m}^{-3}$ for GOM. Close to $50 \%$ of the GOM values were under the detection limit, whereas $98 \%$ of all PBM values were higher than the detection limit.

\subsection{Origin of air masses reaching the Råö site}

Results of the back-trajectory analysis are shown in Fig. 3a, b, c and d. About one-third of the air masses entering the Råö site during the investigated period arrived via the sectors 202.5 to $270^{\circ}$ as shown in Fig. 3a. The GEM concentration as a function of the origin of air masses is almost evenly distributed in the sectors 0 to $90^{\circ}$ and 247.5 to $360^{\circ}$ with an average value of $1.36 \mathrm{ng} \mathrm{m}^{-3}$ as shown in Fig. 3b. The highest GEM values are associated with air masses that passed through the sectors 90 to $247.5^{\circ}$ with an average concentration of $1.51 \mathrm{ng} \mathrm{m}^{-3}$ and a maximum value of $1.71 \mathrm{ng} \mathrm{m}^{-3}$ in the sector $135-157.5^{\circ}$. The elevated GEM values within this sector are presumably mainly due to mercury sources in Poland, Romania, Bulgaria, Greece and from some Balkan countries. Coal combustion for the production of electricity and domestic heating, but also smelters and other industrial activities, is the likely source of mercury. Based on these findings, the sectors 0 to $90^{\circ}$ and 247.5 to $360^{\circ}$ were classified as mainly associated with background air that is not affected by regional mercury emission sources. This assumption is further supported by the PBM measurements as shown in Fig. 3c. Particulate mercury has been proven to be a sensitive marker for polluted air containing mercury (Wängberg et al., 2003). The highest PBM concentrations were found in air from the south-eastern sector as also is the case with GEM, but the difference in PBM concentration between different sectors is much greater. The GOM values show a similar pattern with elevated concentrations in the air from the south-east as shown in Fig. 3d. However, in contrast to PBM, relatively high GOM concentrations were also observed in air masses originating from the north and east, indicating an additional source other than direct anthropogenic sources. 

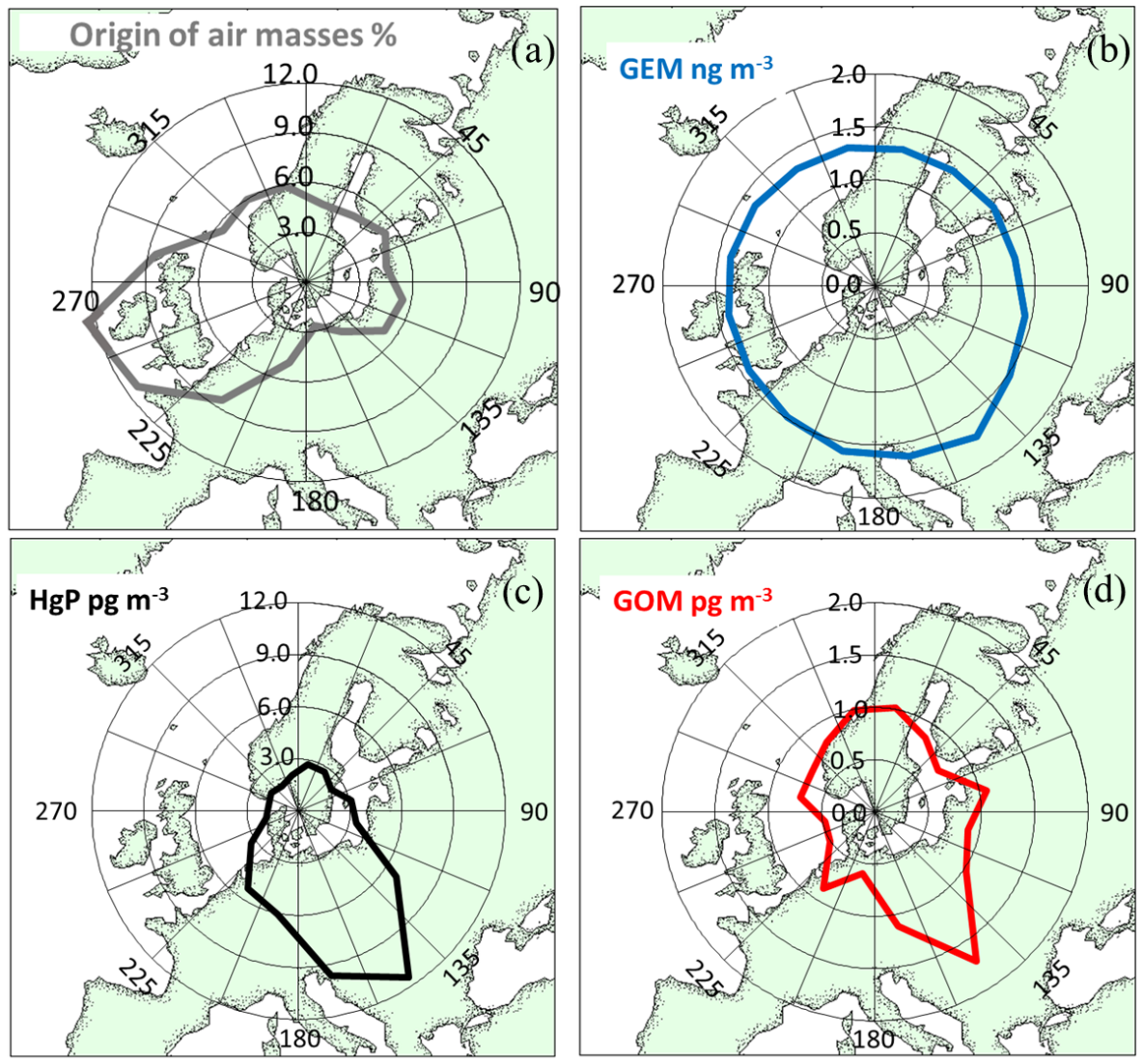

Figure 3. Results of the back-trajectory analysis. (a) Origin of air masses reaching the Råö site presented as relative frequency (\%) within each sector. Panels (b), (c) and (d) show GEM, PBM and GOM concentrations as a function of origin of air masses entering the measurement site.

According to the classification of background and polluted air masses given above it was found that the Råö site receives air of background origin $59 \%$ of the time with average concentrations of GEM, GOM and PBM equal to $1.36 \mathrm{ng} \mathrm{m}^{-3}$, 0.76 and $2.15 \mathrm{pg} \mathrm{m}^{-3}$ respectively. Average GEM, GOM and PBM concentrations associated with polluted air masses yielded concentrations of $1.51 \mathrm{ng} \mathrm{m}^{-3}, 0.85$ and $5.71 \mathrm{pg} \mathrm{m}^{-3}$ respectively.

\subsection{Background and polluted air masses}

The GEM, PBM and GOM values were divided into monthly averages and into background and polluted air masses according to the classification made in Sect. 3.2. The result is shown in Fig. 4. Figure 4a shows average monthly GEM concentrations. A seasonal variation with high values during the cold season is clearly depicted, as well as a difference between air masses associated with background and polluted air. The higher values during winter are an effect of higher mercury emissions from coal combustion etc. in combination with lower mixing heights during winter. Hence, it seems like both background and polluted air masses are influenced by anthropogenic emissions. A similar result is ob- tained with PBM, as shown in Fig. 4b, although the difference between background and polluted air masses is much more pronounced. The GOM data, on the other hand, shows a quite different pattern, with high values mostly occurring during the warm season as shown in Fig. 4c. Another difference is that the GOM concentration in background air may be higher than in polluted air, as is shown by the measurements obtained for May, June and August. As is indicated by Fig. 3d, there is a coupling between elevated GOM concentrations and import of polluted air masses to the Råö site. However, the present results also strongly suggest an additional source, which is likely to stem from the formation of GOM in the atmosphere. At the Råö site, elevated concentrations of GOM were only observed during the daytime at dry and sunny weather with the highest concentrations occurring during spring and summer. Diurnal patterns with peak concentrations at midday or in the early afternoon were observed and often repeated for several days during periods with fair weather. Like for ozone, the diurnal variation is likely to be caused by nocturnal inversion at night, a phenomenon that occurs during clear sky conditions. GOM is then depleted due to deposition on the sea surface, vegetation and on wet 

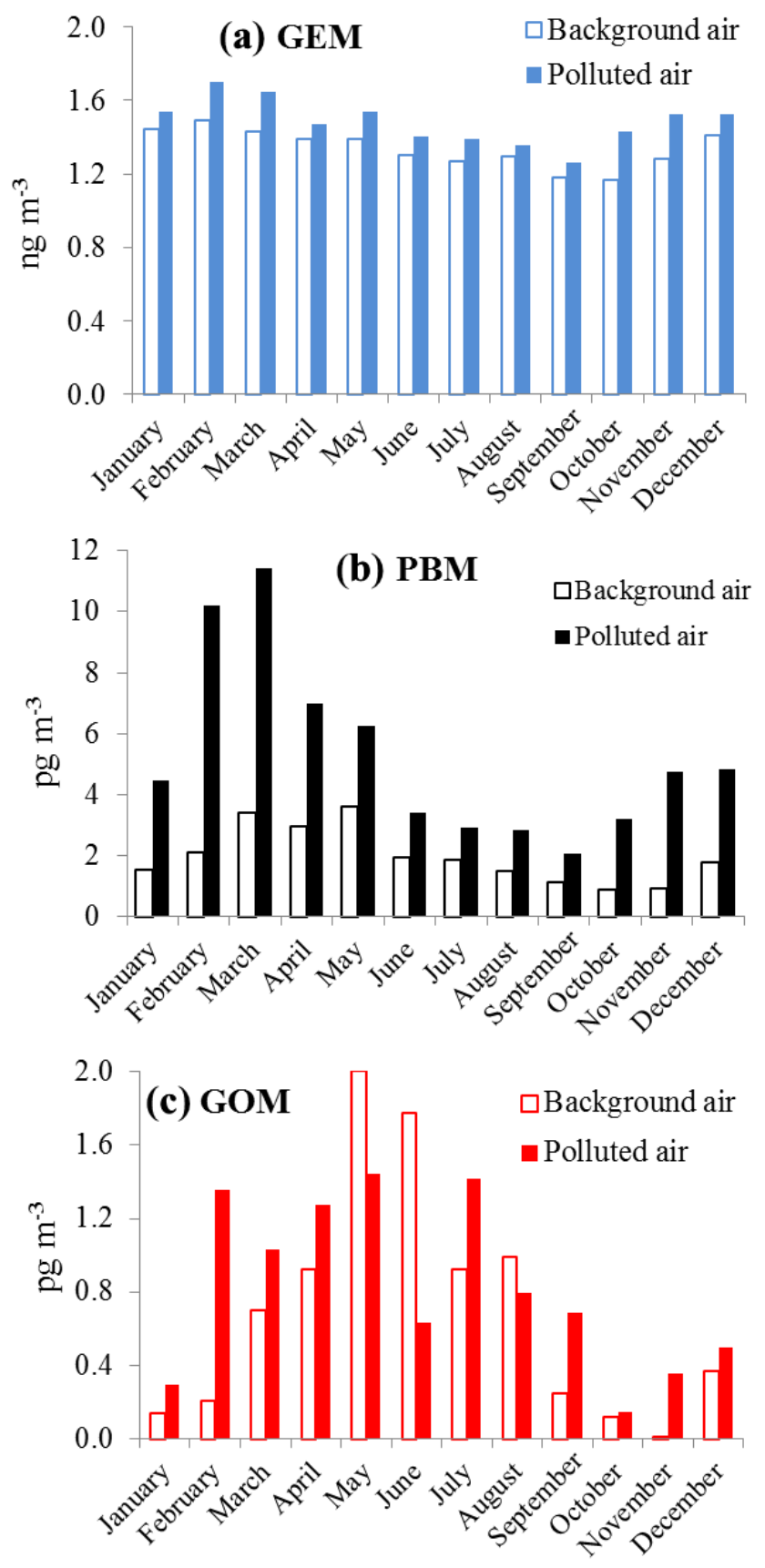

Figure 4. Average mercury air concentrations as a function of month and origin of air masses at the Råö measurement site. The values represent monthly averages of all data from the measurements made from 15 May 2012 to 29 April 2015.

aerosols. The inversion prevents GOM from above from mixing with the air below until the next morning when the inversion is broken by the sun and GOM from above is transferred to the ground through vertical mixing. The diurnal variation of ozone is well documented in the literature (Garland and Derwent, 1979; Zhang and Rao, 1999; Coyle et al., 2002). Råö is a coastal site which means that nocturnal inversions there are normally not as strong as at low-altitude inland locations. Nevertheless, when comparing the daily GOM variation at the Råö site, with that of ozone one see that it almost perfectly coincides with the morning increase and evening decrease of ozone. Ozone is a secondary pollutant that is formed in the atmosphere via atmospheric photolysis reactions and transported to the Råö site rather than being formed locally. Likewise, GOM may also be formed in the troposphere by oxidation of GEM. The GOM formation is likely to be caused by a bromine-driven photolytic oxidation process (Donohoue et al., 2006; Obrist et al., 2011). GOM is probably formed at a slow rate in the atmosphere and, due to its solubility, it is efficiently being scavenged by atmospheric cloud droplets and, therefore, has a short residence time in the atmosphere. However, elevated concentrations may build up during dry atmospheric conditions in the free troposphere and transported to the lower atmosphere by vertical mixing (Wängberg et al., 2007b). From measurements at the Storm Peak Laboratory (in Rocky Mountains, Colorado, USA) at an elevation of $3200 \mathrm{~m}$ a.s.l., Faïn et al. (2009) found evidence for formation and enrichment of GEM in the free troposphere as also has been observed in airborne measurements in the troposphere (Lyman and Jaffe, 2012; Brooks et al., 2014). Elevated levels of GOM were observed both during the day and at night. GOM did not correlate with traces such as $\mathrm{CO}$ and aerosols, indicating that it was not primarily due to anthropogenic pollution sources. Relative humidity was the dominant factor affecting the concentration, with high GOM levels always present whenever relative humidity was below 40 to $50 \%$. Faïn et al. (2009) also found evidence that GOM in the free troposphere may be transported, due to subsidence, entrainment processes and deep vertical mixing, throughout the troposphere and even into the boundary layer under dry cloudless conditions. That GOM, formed aloft in the atmosphere, may be transported to the ground is also supported by ground-based measurements at three sites in Nevada, USA (Weiss-Penzias et al., 2009). The authors found that, in addition to in situ photochemical production, convective mixing and entrainment of dry air from the free troposphere during the day was an important contributor to the observed diurnal GOM pattern measured, in particular at one of the Nevada sites, a remotely located area far away from urban sources of GOM. Like at Råö, the GOM concentrations in Nevada displayed a diurnal pattern that was positively correlated to ozone. The tropospheric origin of GOM measured at the Råö site is further supported by the fact that the highest GOM values were observed in conjunction to the import of air masses from the north that are not associated with major anthropogenic mercury sources. According to the trajectory analysis, air masses with high GOM concentrations could be traced to the Norwegian Sea, the Greenland Sea and in some cases to the Barents Sea, i.e. sea areas north of Scandinavia. 


\section{Conclusions}

Due to the remote location of the Råö measurement station, it receives background air most of the time. However, elevated concentrations, with air masses coming especially from the south-east, are noticeable. About one-third of the air sampled at Råö has passed the UK and Denmark. Going back some decades earlier a lot of coal was used in the UK for power production and domestic heating. As a result, a lot of sulfur, and probably also mercury, was received and deposited in Scandinavia. The present investigation shows that little if any mercury originates from the UK or Denmark today as a consequence of shift from coal to cleaner power production techniques. Mercury emissions from other countries, including Sweden, have also dramatically reduced since 1990. During the period from 1985 to 1989 , the average TGM concentration at the Råö site was as high as $3.2 \mathrm{ng} \mathrm{m}^{-3}$ (Iverfeldt et al., 1995).

At Råö, the airborne mercury species investigated all have a direct anthropogenic component; i.e. they can be attributed to regional mercury sources, as well as to a background atmospheric origin. This is especially true of GEM, due to its long atmospheric residence time. The background concentration of GEM in the northern marine hemisphere is likely to resemble that measured at Mace Head. Particulate bound mercury has a much shorter atmospheric residence time, but small particles with an aerodynamic diameter of less than $2.5 \mu \mathrm{m}$ may stay in the atmosphere long enough to contribute to a background level of PBM. Due to the normally short atmospheric lifetime of GOM, one may not expect to receive air masses of remote origin with substantial concentrations of GOM by the same means as with GEM and PBM. According to the kinetics of the atmospheric oxidation process of GEM to GOM (Donohoue et al., 2006), elevated concentrations of GOM are not likely to be formed locally in the air near background measurement sites. Hence, elevated GOM concentrations measured in background air at the Råö site presumably originate from air masses enriched in mercury from the free troposphere, something that may occur during dry atmospheric conditions. As far as we know, this is the first time that real evidence of tropospheric-formed GOM has been observed from ground-based measurements in Europe.

Acknowledgements. The financial support from The European Commission, FP7 (contract no. 26511) is gratefully acknowledged.

Edited by: F. Sprovieri

Reviewed by: J. Knœry and one anonymous referee

\section{References}

AMAP/UNEP: Technical Background report for the Global Mercury Assessment, available at: http://www.amap.no/documents/doc/, 2013.

Brooks, S., Ren, X., Cohen, M., Luke, W. T., Kelley, P., Artz, R., Hynes, A., Landing, W., and Martos, B.: Airborne Vertical Profiling of Mercury Speciation near Tullahoma, TN, USA, Atmosphere, 5, 557-574, doi:10.3390/atmos5030557, 2014.

Brown, R. J. C., Pirrone N., van Hoek, C., Sprovieri, F., Fernandez, R., and Toté, K.: Standardisation of a European measurement method for the determination of total gaseous mercury: results of the field trial campaign and determination of a measurement uncertainty and working range, J. Environ. Monit., 12, 689-695, 2010.

Coyle, M., Smitha, R. I., Stedman, J. R., Weston, K. J., and Fowler, D.: Quantifying the spatial distribution of surface ozone concentration in the UK, Atmos. Environ., 36, 1013-1024, 2002.

Donohoue, D. L., Bauer, D., Cossairt, B., and Hynes, A. J.: Temperature and Pressure Dependent Rate Coefficients for the Reaction of $\mathrm{Hg}$ with $\mathrm{Br}$ and the Reaction of $\mathrm{Br}$ with $\mathrm{Br}$ : A Pulsed Laser Photolysis-Pulsed Laser Induced Fluorescence Study, J. Phys. Chem. A, 110, 6623-6632, 2006.

Draxler, R. R.: Evaluation of an ensemble dispersion calculation, J. Appl. Meterol., 42, 308-317, 2003.

Faïn, X., Obrist, D., Hallar, A. G., Mccubbin, I., and Rahn, T.: High levels of reactive gaseous mercury observed at a high elevation research laboratory in the Rocky Mountains, Atmos. Chem. Phys., 9, 8049-8060, doi:10.5194/acp-9-8049-2009, 2009.

Garland, J. A. and Derwent, R. G.: Destruction at the ground and the diurnal cycle of concentration of ozone and other gases, Q. J. Roy. Meteorol. Soc., 105, 169-183, 1979.

Gustin, M. S., Huang, J., Miller, M. B., Peterson, C., Jaffe, D. A., Ambrose, J., Finley, B. D., Lyman, S. N., Call, K., Talbot, R., Feddersen, D., Mao, H., and Lindberg, S. E.: Do We Understand What the Mercury Speciation Instruments Are Actually Measuring? Results of RAMIX, Environ. Sci. Technol., 47, 7295-7306, doi:10.1021/es3039104, 2013.

Gustin, M. S., Amos, H. M., Huang, J., Miller, M. B., and Heidecorn, K.: Measuring and modeling mercury in the atmosphere: a critical review, Atmos. Chem. Phys., 15, 5697-5713, doi:10.5194/acp-15-5697-2015, 2015.

Iverfeldt, A., Munthe, J., Brosset, C., and Pacyna, J.: Longterm changes in concentration and deposition of atmospheric mercury over Scandinavia, Water Air Soil Poll., 80, 227-233, 1995.

Jaffe, D. A., Lyman, S. Amos, H. M., Gustin, M. S., Huang, J., Selin, N. E., Levin, L., Schure, A., Mason, R. P., Talbot, R., Rutter, A., Finely, B., Jaegleì, L., Shah, V., McClure, C., Ambrose, J., Gratz, L., Lindberg, S., Weiss-Penzias, P., Sheu, G-R., Feddersen, D., Horvat, M., Dastoor, A., Hynes, J. H., Mao, H., Sonke, J. E., Slemr, F., Fisher, J. A., Ebinghaus, R., Zhang, Y., and Edwards, G.: Progress on Understanding Atmospheric Mercury Hampered by Uncertain Measurements, Environ. Sci. Technol., 48, 7204-7206, doi:10.1021/es5026432, 2014.

Kentisbeer, J, Leeson, S. R., Malcolm, H. M., Leith, I. D., Braban, C. F., and Cape, J. N.: Patterns and source analysis for atmospheric mercury at Auchencorth Moss, Scotland, Environ. Sci. Process. Imp., 16, 1112-1123, doi:10.1039/C3EM00700F, 2014.

Kentisbeer, J., Leeson, S. R., Clark, T., Malcolm, H. M., and Cape J. N.: Influences on and patterns in total gaseous mercury (TGM) 
at Harwell, England, Environ. Sci. Process. Imp., 17, 586-595, 2015.

Lamborg, C. H., Fitzgerald, W. F., O’Donnell, J., and Torgersen, T.: A non-steady-state compartment model of global-scale mercury biochemistry with interhemispheric atmospheric gradients, Geochim. Cosmochim. Ac., 66, 1105-1118, 2002.

Landis, M. S., Stevens, R. K., Schadelish, F. S., and Prestbo, E. M.: Development and Characterization ofan Annular Denuder Methodology for the Measurement of Divalent Inorganic Reactive Gaseous Mercury in Ambient Air, Environ. Sci. Technol., 36, 3000-3009, 2002.

Lindberg, S. E., Brooks, S., Lin, C. J., Scott, K. J., Landis, M. S., Stevens, R. K., Goodsite, M., and Ritcher, A.: Dynamic oxidation of gaseous mercury in the Arctic troposphere at polar sunrise, Environ. Sci. Technol., 36, 1245-1256, 2002.

Lyman, S. N. and Jaffe, D. A.: Formation and fate of oxidized mercury in the upper troposphere and lower stratosphere, Nat. Geosci., 114-117, doi:10.1038/ngeo1353, 2012.

Obrist, D., Tas, E., Peleg, M., Matveev, V., Faïn, X., Asaf, D., and Luria, M.: Bromine-induced oxidation of mercury in the mid-latitude atmosphere, Nat. Geosci., 4, 22-26, doi:10.1038/ngeo1018, 2011

Olson, M. L. and Rhodes, M, F.: NADP AMNet Standard Operating Procedures for Field Analysis of Gaseous and Fine ParticulateBound Mercury, Version 1.1, National Atmospheric Deposition Program (NADP), available at: http://nadp.isws.illinois.edu, 2011.

Pacyna, J. M., Travnikov, O., De Simone, F., Hedgecock, I. M., Sundseth, K., Pacyna, E. G., Steenhuisen, F., Pirrone, N., Munthe, J., and Kindbom, K.: Current and future levels of mercury atmospheric pollution on a global scale, Atmos. Chem. Phys., 16, 12495-12511, doi:10.5194/acp-16-12495-2016, 2016.

Schroeder, W. H. and Munthe, J.: Atmospheric Mercury - an overwiew, Atmos. Environ., 32, 809-822, 1998.

Slemr, F., Weigelt, A., Ebinghaus, R., Kock, H. H., Bödewadt, J., Brenninkmeijer, C. A. M., Rauthe-Schöch, A., Weber, S., Hermann, M., Becker, J., Zahn, A., and Martinsson, B.: Atmospheric mercury measurements onboard the CARIBIC passenger aircraft, Atmos. Meas. Tech., 9, 2291-2302, doi:10.5194/amt-92291-2016, 2016.
Steffen, A., Scherz, T., Ohlson, M., Gay, D., and Blanchard P.: A comparison of data quality control protocols for atmospheric mercury speciation measurements, J. Environ. Monit., 14, 752765, doi:10.1039/c2em10735j, 2012.

Swartzendruber, P. C., Jaffe, D. A., and Finley, B.: Improved fluorescence peak integration in the Tekran 2537 for applications with sub-optimal sample loadings, Atmos. Environ., 43, 36483651, 2009.

Weigelt, A., Temme, C., Bieber, E., Schwerin, A., Schuetze, M., Ebinghaus, R., and Kock, H. K.: Measurements of atmospheric mercury species at a German rural background site from 2009 to 2011 - methods and results, Environ. Chem., 10, 102-110, doi:10.1071/EN12107, 2013.

Weiss-Penzias, P., Gustin, M. S., and Lyman, S. N.: Observations of speciated atmospheric mercury at three sites in Nevada: Evidence for a free tropospheric source of reactive gaseous mercury, J. Geophys. Res., 114, D14302, doi:10.1029/2008JD011607, 2009.

Wängberg, I., Munthe, J., Ebinghaus, R., Gårdfeldt, K., Iverfeldt, $\AA$., and Sommar, J.: Distribution of TPM in Northern Europe, Sci. Total Environ., 304, 53-59, 2003.

Wängberg, I., Munthe, J., Berg, T., Ebinghaus, R., Kock, H. H., Temme, C., Bieber, E., Spain, T. G., and Stolk, A.: Trends in air concentration and deposition of mercury in the coastal environment of the North Sea Area, Atmos. Environ., 41, 2612-2619, 2007a.

Wängberg, I., Munthe, J., Amouroux, D., Andersson, M. E., Fajon, V., Ferrara, R., Gårdfeldt, K., Horvat, M., Mamane, Y., Melamed, E., Monperrus, M., Ogrinc, N., Yossef, O., Pirrone, N., Sommar, J., and Sprovieri, F.: Atmospheric mercury at mediterranean coastal stations, Environ. Fluid Mech., 8, 101116, doi:10.1007/s10652-007-9047-2, 2007b.

Zhang, J. and Rao, S. T.: The Role of Vertical Mixing in the Temporal Evolution of Ground-Level Ozone Concentrations, J. Appl Meteorol., 38, 1674-1691, 1999. 